1 Universidade Estadual Vale do Acaraú (UVA) Sobral (CE), Brasil. jacyaraalvessousa@gmail. com

2 Universidade Federal do Ceará (UFC) - Sobral (CE), Brasil.

\section{Formação política na graduação em enfermagem: o movimento estudantil em defesa do SUS}

\author{
Political education in undergraduate Nursing courses: the student \\ movement in defense of the SUS
}

Jaciara Alves Sousa', Quitéria Larissa Teodoro Farias², Mariana Moreira da Costa', Antônio

Ademar Moreira Fontenele Júnior ${ }^{1}$

DOI: $10.1590 / 0103-11042019 S 525$

RESUMO O movimento estudantil configura-se como um espaço de expressão política na saúde, deixando marcas importantes na construção e na implantação do Sistema único de Saúde (SUS). Nos cursos de enfermagem, esses ambientes são materializados pela participação nos Centros e Diretórios Acadêmicos e proporcionam o entendimento de fatores e problemas do contexto social, o que permite o conhecimento da realidade pelos discentes. Este estudo trata-se de um relato de experiência, construído por meio das mobilizações proporcionadas pelo Centro Acadêmico Wanda de Aguiar Horta do curso de Enfermagem da Universidade Estadual Vale do Acaraú em Sobral, Ceará, no período de 2017 a 2019, abordando as contribuições do movimento estudantil na sustentabilidade do SUS. Percebe-se que o movimento estudantil representa um processo de mobilização e resistência contra o desmonte do SUS expresso por meio da exposição e do debate de opiniões na luta a favor da melhoria da atenção à saúde pública. Na formação em enfermagem, enquanto categoria com participação expressiva da composição dos colaboradores do SUS, esses movimentos objetivam a criação de uma comunidade acadêmica mais politizada e atuante. Assim, nessa realidade de tentativa de descontinuidade do SUS, percebe-se a importância do resgate do protagonismo estudantil nas lutas sociais com finalidade de contribuir para superar essa realidade de retrocesso.

PALAVRAS-CHAVE Sistema Único de saúde. Formação continuada. Enfermagem.

\begin{abstract}
The student movement is a space for political expression in health, leaving important marks in the construction and implementation of the Unified Health System (SUS). In Nursing courses, these environments are materialized through participation in the Academic Centers and Directories and provide the understanding of factors and problems of the social context that allows the students to know the reality. This study is an experience report, built through the mobilizations provided by the Wanda de Aguiar Horta Academic Center of the Nursing course of the Vale do Acaraú State University in Sobral, Ceará, from 2017 to 2019, addressing the student movement in the sustainability of the SUS. It is noted that the student movement represents a process of mobilization and resistance against the dismantling of the SUS, which is expressed through the exposure and debate of opinions in the fight for the improvement of public health care. In nursing education, as a category with significant participation among the SUS's employees, these movements aim to create a more politicized and active academic community. Thus, in this reality of attempting to discontinue the SUS, one can perceive the importance of rescuing student protagonism in social struggles with the purpose of contribute to overcoming this retrogressive reality.
\end{abstract}

KEYWORDS Unified Health System. Education, Continuing. Nursing. 


\section{Introdução}

O movimento estudantil, ainda que com presenças históricas muito distintas, por algum tempo, foi o ator social de maior força e organização, sendo identificado como espaço de formulação de uma nova expressão política. Sua ação reivindicatória e seu posicionamento político perante o Estado durante a ditadura militar protagonizaram grandes manifestos no que se refere ao direito social, político e partidário, aprimorando os estudos sobre política no âmbito acadêmico e a importância do empoderamento estudantil na política nacional'.

Durante o período ditatorial, o movimento estudantil ocupou um considerável espaço no âmbito da esfera pública brasileira, sendo notícia nos meios de comunicação quase diariamente. A diversidade geopolítica das mobilizações estudantis, formas revolucionárias e lugares do seu acontecimento, bem como a vontade coletiva por mudanças daquela realidade, contribuíram para eclodir uma comunidade singular pensada em amplas dimensões, a dos jovens universitários em ação, que ultrapassou os limites da universidade e ganhou espaços em todo o território brasileiro ${ }^{2}$.

No âmbito da saúde, deixou sua marca no processo de construção e implantação do Sistema Único de Saúde (SUS) que nasceu, principalmente, a partir do Movimento da Reforma Sanitária como um amplo projeto de saúde coletiva. Desde a sua criação, o SUS tem avançado muito, no entanto, é necessário que os mobilizadores se manifestem de forma mais imponente ante os desafios existentes em torno de sua consolidação ${ }^{3}$.

Atualmente, na universidade, os Centros e Diretórios Acadêmicos se constituem como espaços legitimados para o primeiro contato do estudante com o movimento estudantil. A vivência nesse ambiente, fora da sala de aula, propicia a identificação e o entendimento de fatores e problemas do contexto social, permitindo ao estudante conhecer sua realidade. Além disso, amplia-se a compreensão do papel e da prática na futura profissão ${ }^{4}$.
$\mathrm{Na}$ formação em enfermagem, esses ambientes se configuram como um espaço de grande formação política, social e humanística para fortalecimento do SUS. Considerada atualmente como a "espinha dorsal do sistema de saúde" , essa prática contribui de forma decisiva para o entendimento do papel do profissional de enfermagem dentro de uma estrutura social muitas vezes desigual e excludente, que perpassa por períodos de incertezas no que concerne à sustentabilidade de um sistema único, universal e igualitário ${ }^{6}$.

A participação no Centro Acadêmico em Enfermagem é realizada sob condições políticas de discentes para discentes, ocorrendo sob regime de votação por concorrência entre chapas ou por alternativa de aceitação de chapa única, sendo, portanto um exercício da cidadania, de direitos e deveres sociais, políticos e civis ${ }^{7}$, contribuindo significativamente para a formação política dos envolvidos no movimento estudantil.

A ênfase deste estudo na formação política em enfermagem se deve não só pela busca de conhecimento cognitivo, mas também pela formação de habilidades na construção de estudantes militantes, pela atuação com desempenho crítico nas práticas de enfermagem e pela necessidade de desenvolver uma atuação como agentes de transformação social na perspectiva de superação do modelo societário excludente e, portanto, socialmente injusto ${ }^{8}$.

Em tempos de avanços, desafios e retrocessos, faz-se importante refletir acerca de experiências que atuam na defesa e fortalecimento do SUS. Com isso, o presente artigo tem a proposta de compartilhar experiências de acadêmicos de enfermagem na dialógica da formação política em prol da sustentabilidade do SUS durante as vivências no Centro Acadêmico de Enfermagem Wanda de Aguiar Horta.

\section{Material e métodos}

O estudo se delineia em um relato de experiência, construído por meio das mobilizações 
desenvolvidas pelo Centro Acadêmico Wanda de Aguiar Horta (CAWAH) do curso de Enfermagem da Universidade Estadual Vale do Acaraú (UVA), Sobral, Ceará, nas gestões de 2017-2018 e 2018-2019, abordando, portanto, as contribuições do movimento estudantil atual/ local na sustentabilidade do SUS.

O relato de experiência é um tipo de estudo que possibilita a abordagem de vivências humanas, articulado à sua contextualização por meio da literatura pertinente e das narrativas dos autores, relacionando com o saber técnico-científico?.

O CAWAH é composto por 13 membros, sendo estes representantes discentes de todos os semestres do curso de enfermagem e tem sua organização em formato de coordenações, prezando pela horizontalidade dos processos, a saber: coordenação geral (um coordenador e um adjunto), coordenação de arquivos e secretaria (um coordenador e um adjunto), coordenação de finanças (um coordenador e um adjunto), coordenação de assuntos socioculturais (um coordenador), coordenação de comunicação (um coordenador) coordenação de formação (um coordenador e dois adjuntos) e a coordenação de articulação interinstitucional (um coordenador e um adjunto).

Há, portanto, um processo eleitoral democrático para a escolha da chapa representante, no qual todos os estudantes regularmente matriculados no curso têm direito ao voto. Todas as ações realizadas pelo CAWAH são previstas em estatuto, cada coordenação tem sua responsabilidade específica dentro da entidade e cabe a todos lutar em prol dos direitos dos estudantes, defendendo a enfermagem como categoria fundamental para a efetivação da saúde enquanto direito de todos e dever do Estado ${ }^{10}$, em defesa de um sistema universal de saúde.

Nesse ínterim, os resultados aqui apresentados e discutidos representam a corresponsabilização do CAWAH, enquanto movimento estudantil, na incansável luta de fortalecimento do SUS, ante os desafios enfrentados, no âmbito político de formação e atuação profissional em enfermagem.
Compreendendo as inúmeras atividades dessa natureza desenvolvidas, houve a necessidade de selecionar as de maiores impactos sociopolíticos corroborando o objetivo do estudo. Dessa forma, foram delimitados os eixos analíticos: Mobilização e resistência: assembleias gerais em defesa do SUS e da valorização da enfermagem; Fortalecimento da formação política em enfermagem; e Não ao desmonte do SUS.

\section{Resultados e discussões}

\section{Mobilização e resistência: assem- bleias gerais em defesa do SUS e da valorização da enfermagem}

A assembleia configura-se como um espaço democrático e deliberativo que permite discussões sobre possibilidades e entraves acerca de temas de interesse para os seus participantes. Se conduzida corretamente proporciona discussões coletivas que conferem requisitos para o empoderamento dos envolvidos ${ }^{11}$.

O CAWAH vem utilizando do espaço favorecido pela assembleia para proporcionar discussões perante os desafios enfrentados, no que concerne à necessidade de empoderamento da enfermagem enquanto profissão autônoma e científica para o desenvolvimento de estratégias, principalmente relacionadas com as atribuições na Estratégia Saúde da Família (ESF) no âmbito do SUS, bem como na formação acadêmica, diante das fragilidades enfrentadas.

Em outubro de 2017, o atendimento de enfermagem sofreu um retrocesso que provocou prejuízos não apenas para a categoria, mas para o atendimento dos usuários do SUS. A $20^{\mathrm{a}}$ vara cível do Distrito federal lançou uma liminar impedindo que os profissionais de enfermagem realizassem solicitações de exames, atribuindo essa competência somente à profissão médica ${ }^{12}$.

No entanto, tendo conhecimento de que a aplicação do processo de enfermagem constitui uma atividade privativa do enfermeiro e, 
nesse contexto a prescrição de medicamentos $^{\mathbf{1 3}}$, bem como a solicitação de exames de rotina e complementares ${ }^{\mathbf{1 4}}$ dentro da rotina de serviços e sob aprovação de instituições de saúde, todas as instâncias colegiadas e movimentos sociais de saúde se uniram contra a referida decisão.

Além disso, compreender a importância da enfermagem é fundamental uma vez que a atuação desse profissional vem sendo constantemente ampliada nacional e internacionalmente. No âmbito do SUS, especificamente, esse profissional exerce papel decisivo e proativo no que tange à identificação de necessidades de cuidado assim como na promoção e proteção da saúde dos indivíduos ${ }^{15}$.

Diante do cenário referido e a partir de inquietações relacionadas com ele, realizou-se uma assembleia geral com enfermeiros da regional de Sobral, Ceará, para discussão e debate acerca das situações vivenciadas pela assistência de enfermagem em decorrência dos efeitos provocados pela liminar. $\mathrm{O}$ momento foi proporcionado pelo CAWAH em parceria com a coordenação do curso de enfermagem da UVA e todo o corpo docente, o Conselho Regional de Enfermagem (Coren) e a Residência Multiprofissional em Saúde da Família da Escola de Saúde Pública Visconde de Sabóia (ESPVS).

A assembleia contou com cerca de 260 participantes, entre eles, acadêmicos de enfermagem, enfermeiros e técnicos de toda a região norte do Ceará, das mais diversas áreas de atuação. Estiveram presentes representação do Coren-CE, do movimento estudantil de instituições públicas e privadas de Sobral, enfermeiros docentes, assistencialistas, gestores e representantes políticos, todos unidos em prol do fortalecimento da categoria.

As discussões giraram em torno da mobilização da enfermagem a favor do retorno das atribuições inerentes à profissão, bem como para demonstrar o reflexo dessa decisão na assistência ofertada pelo SUS, com importantes falas dos profissionais que estão na luta do dia a dia da assistência, seja ela na ESF, como na área hospitalar, ao encontro do discurso dos que se encontram na linha de frente das lutas sociopolíticas da profissão, como deputados, vereadores, o presidente e representantes do conselho de classe presentes.

A liminar foi derrubada, e a reflexão é de que esse movimento se fez como um convite a enfermagem de todo o País para assumir seu papel político e social, contribuindo para a saúde, a cidadania e a democracia. Enquanto protagonismo estudantil do CAWAH, remete ainda ao papel social da universidade, instigando a formação de um enfermeiro comprometido com os tempos de adversidade política, formando agentes de transformação da sociedade ${ }^{16}$.

Em março de 2018, os movimentos se voltaram para a formação, o curso de enfermagem sofria com grandes lacunas no que concerne ao ensino e preceptorias de estágio, acarretando prejuízos na formação dos estudantes. A atual conjuntura se dava pela finalização dos contratos dos docentes temporários e pela impossibilidade de contratação por nova seleção em razão de barreiras judiciais.

Foi então organizada pelo CAWAH uma assembleia no curso para que juntos, discentes e docentes, pudessem discutir as fragilidades vivenciadas, buscando estratégias de melhorias. Contou-se com a participação de 130 discentes e 6 docentes, incluindo a coordenadora do curso e a vice-reitora da universidade. Como fruto do momento, foi construída coletivamente uma carta aberta ao juiz responsável pelo julgamento do pleito, informando os prejuízos acarretados pela demora dos processos tanto ao curso, quanto a cidade de Sobral, que conta com a contribuição dos estudantes no Sistema Saúde Escola (SSE).

Durante o momento, foi destacado a precarização do ensino nas universidades públicas, não sendo isso restrito à presente instituição. Leonello e Oliveira ${ }^{17}$, em estudo realizado que buscou mostrar o processo de trabalho docente em enfermagem em diferentes contextos, apontam que a precarização e a flexibilização do trabalho se manifestam de diversas 
formas, e como principais aspectos, enfatizam as limitações estruturais e de infraestrutura material e humana, o que vai ao encontro da realidade vivenciada.

A carta construída foi entregue pessoalmente por membros do CAWAH ao juiz, fortalecendo o protagonismo estudantil, o exercício da cidadania e a representação dos estudantes que são os mais prejudicados diante da situação, o que contribuiu para o solucionamento mais hábil da problemática.

\section{Fortalecimento da formação política em enfermagem}

Desde 2001, vem sendo discutido por Slaughter e Leslie ${ }^{18}$ o capitalismo acadêmico a fim de refletir como a universidade vem atendendo às demandas neoliberais do modelo capitalista nos países hegemônicos, tratando o ensino como parte de uma política econômica. No Brasil, percebe-se que a mercantilização no ensino superior tem avançado em larga escala por diversos fatores, entre eles, o aumento de Instituições de Ensino Superior (IES) privadas, com fins lucrativos e negociações de suas ações em bolsas de valores ${ }^{19}$.

Esse interesse econômico por trás do ensino superior vem proporcionando uma realidade cada vez mais crescentes na abertura de cursos na área da saúde sem que haja comprometimento com uma formação fortalecida no tripé do ensino-pesquisa-extensão.

Na enfermagem, crescem cada vez mais as discussões acerca da graduação na modalidade de Ensino a Distância (EAD). Acredita-se que o ensino de enfermagem nessa modalidade pode acarretar prejuízos significativos para os pacientes, tendo em vista a necessidade de aquisição de competência e habilidades para execução de atribuições práticas desses profissionais ${ }^{20}$.

Tal fato ocorreu em razão da revogação do Ministério da Educação e Cultura (MEC) da portaria de $\mathrm{n}^{\circ} 8.754 / 2016$ que gerava dificuldades para a abertura dos cursos de enfermagem na modalidade de $\mathrm{EAD}$, processo este que foi encarado de forma negativa para a formação em enfermagem ${ }^{21}$.

Sabe-se que entre as competências dos profissionais de enfermagem estão aquelas em que há contato direto com o paciente, inclusive na realização de procedimentos invasivos. Ressalta-se que tais habilidades não podem ser conquistadas de forma subjetiva ou pela utilização de material sintético para treinamento, necessitando, portanto, do contato pele a pele. Além disso, a comunicação interpessoal realizada nesse processo favorece o exercício das relações interpessoais, uma das principais ferramentas de atuação da enfermagem.

Nesse sentido, no mês de abril de 2018, foi realizado, pela parceria CAWAH e Coren/ $\mathrm{CE}$, um fórum contra o ensino de enfermagem a distância para debate sobre o tema. $\mathrm{O}$ espaço foi oportuno para o esclarecimento de dúvidas acerca dos prejuízos que a modalidade de ensino acarretaria para a atuação e para a visibilidade da enfermagem.

Contou-se com a participação de acadêmicos de enfermagem, enfermeiros e usuários do SUS, em que foram incluídos nos debates os temas relacionados com a qualidade do ensino para o fortalecimento da categoria, com a necessidade de conhecimento científico para atuação concreta da enfermagem e com os aspectos jurídicos que envolvem o tema em questão.

Além disso, o momento também proporcionou a união de todos os acadêmicos do curso de enfermagem a favor de uma causa importante para a formação, bem como possibilitou a construção de opiniões acerca do tema discutido embasadas pelo conhecimento técnico-científico, de maneira a colaborar com a formação política dos envolvidos. É essencial o incentivo à aquisição de autonomia do estudante de graduação em enfermagem por meio de experiências exitosas no ambiente acadêmico, para que reflitam positivamente no seu campo de atuação profissional22.

A parceria do movimento estudantil, expressa pelo CAWAH, às representações do conselho de classe da enfermagem, na figura do Coren/CE, garante aos discentes apropriação 
cognitiva e política sobre a profissão, fortalecendo as lutas referentes à categoria.

Essa parceria surge da necessidade de estudantes de entenderem seu papel no fortalecimento da categoria e de entenderem a importância da militância na busca de um SUS melhor e de qualidade na oferta de serviços para a população. O SUS foi e continua sendo uma grande conquista de toda a sociedade, dessa forma, a parceria Coren e CAWAH possibilitou a criação de uma ponte entre a Universidade e a realidade local na discussão dos principais desafios a serem enfrentados, criando possibilidades criativas para resolução dos problemas, além de empoderar os discentes na vivência desse processo.

Tendo em vista a importância do Conselho Federal de Enfermagem e dos Conselhos Regionais para a institucionalização do exercício da profissão, entender sua importância desde a graduação se torna fundamental no entendimento na luta por melhoria na categoria e pelo SUS - principal local de trabalho dos enfermeiros -, além de fortalecer a identidade profissional deles. Portanto, o vínculo entre o conselho de enfermagem e a universidade demonstra que essa integração entre dois polos representativos torna a profissão forte, competente e reconhecida. Essa experiência possibilita ao acadêmico visibilidade e bons exemplos de profissionais habilitados para um exercício da profissional ético e legal, que garante uma assistência à saúde livre de riscos de imperícia, imprudência e negligência, bem como profissionais comprometidos ético e politicamente com os princípios que regem o SUS ${ }^{23}$.

Entre os campos de expressão política e atuação do CAWAH, há ainda a participação efetiva no Conselho Municipal de Saúde de Sobral. Enquanto entidade deliberativa e fiscalizadora, o membro participante tem direito de voz nas decisões de saúde locais e se faz como uma representação estudantil importante para garantir e fortalecer o espaço formativo do SSE. Todas as discussões pertinentes são levadas para os estudantes mediantes rodas de conversas mensais mediadas pelo CAWAH com os líderes de cada semestre letivo.
Ante as demandas da Universidade, em novembro de 2018, teve início o processo de renovação da estatuinte da instituição, em que o movimento estudantil tem papel fundamental nessa atuação. É na estatuinte que se define o estatuto da universidade, que compreende o conjunto de leis internas que irá reger a sua existência. Como forma de transformar a instituição a partir das necessidades vigentes ${ }^{24}$, o CAWAH junto com os demais Centros Acadêmicos e do Diretório Central dos Estudantes (DCE), puderam levantar questões importantes no que diz respeito às necessidades de cada curso e de como a universidade se articula em seu contexto geral.

A ação e o efeito de participar incluem importantes componentes em um processo democrático, podendo também refletir na forma em que os cidadãos se envolvem nas decisões políticas, organizacionais ou de grupos aos quais estão inseridos. Sendo assim, participar de movimentos no ambiente acadêmico devem ser importantes princípios para desenvolvimento político dos estudantes ${ }^{\mathbf{2 5}}$.

Esse processo reflete a importância de uma comunidade acadêmica conhecedora dos seus direitos e deveres, a necessidade do envolvimento efetivo dos gestores, no intuito de reconhecer a importância da universidade no meio social, e o engajamento político na construção de leis que devem dialogar com as reais necessidades dos discentes e docentes, fortalecendo a formação em saúde, no contexto do curso de enfermagem, voltado para as necessidades do SUS.

\section{Não ao desmonte do SUS}

A criação do SUS pela Constituição de 1988 fez parte de um processo muito amplo de modificações nas relações políticas entre o Estado e a sociedade, que culminou no reconhecimento do setor saúde como direito social a ser contemplado pelas políticas públicas, de acordo com o modelo social-democrata ${ }^{26}$.

Nas variáveis políticas sociais do Brasil, e não apenas na saúde, foi definida, de acordo 
com esse modelo, uma forte base no reconhecimento do direito de cidadania e garantida como dever do Estado. Essa modificação foi possível em circunstâncias históricas difíceis e particulares. Essas circunstâncias determinaram constrangimentos e limitações à implantação do SUS que até hoje cobram seu preço e não foram ainda superados ${ }^{27}$.

Compreendendo a importância das manifestações sociais, acadêmicas e setoriais para garantir o fortalecimento e sustentabilidade do SUS, o CAWAH, em parceria com os sindicatos dos trabalhadores da saúde e com os militantes das Residências Multiprofissionais em Saúde da Família e Saúde Mental da ESPVS, conduziu momentos de diálogo, debate e manifesto em defesa do SUS.

Em setembro de 2018, foi realizada a caminhada dos trabalhadores em defesa do SUS, com participação ativa do CAWAH, de servidores públicos e privados, estudantes de graduação e pós-graduação e representantes dos sindicatos apoiadores da causa. Foi um momento no qual os participantes puderam protestar contra o desfinanciamento do SUS e o descaso com a ESF.

O Município de Sobral possui 36 Centros de Saúde da Família com cobertura de 100\% da população ${ }^{\mathbf{2 8}}$, o que garante excelentes indicadores de saúde. Com o desmonte do SUS, o serviço primário passaria a atender apenas a serviços simples, deixando uma parcela da população sem cobertura da ESF. Com essa medida, os serviços hospitalares seriam sobrecarregados, refletindo em uma assistência à saúde pouco efetiva e igualitária. Assim, o trabalho construído em anos, buscando uma assistência de qualidade e a conquista de excelentes resultados, seria desfeito.

O CAWAH também realizou rodas de conversa em sala de aula com representantes do Coren e representações de grupos estudantis como Ligas Acadêmicas, projetos de extensão e membros do Centro Acadêmico de instituições públicas e privadas de Sobral para diálogo acerca da importância do SUS e da formação acadêmica em enfermagem.
Nesse espaço, foram abordados alguns temas, como: o subfinanciamento do SUS, a necessidade da participação social para o fortalecimento do SUS e a importância da enfermagem na sua construção e manutenção. No decorrer das discussões, identificaram-se a indignação de muitos acadêmicos e a necessidade de realizar alguma manifestação em prol da melhoria do SUS em seus diversos aspectos. A partir disso, foram lançadas propostas de realização de virais nas redes sociais com postagem de esclarecimento sobre a importância do sistema para a população. A estratégia vem sendo replicada, e as postagens têm alcançado um número significativo de pessoas, e vem sendo cada vez mais compartilhadas.

Vale ressaltar que as atividades virtuais realizadas surgem como uma forma complementar à luta corpo a corpo descrita neste artigo. Todas as atividades realizadas só foram possíveis mediante a articulação possibilitada pelas redes sociais, tanto no que diz respeito à organização estrutural dos movimentos como na divulgação para adesão da população e dos profissionais.

Compreendemos, portanto que, apesar de as redes sociais se apresentarem como meios que possibilitam um grande alcance de pessoas, ainda há o desafio de consolidar o espaço virtual como um meio de (re)construção de utopias, de práxis coletiva e política29.

Essa prática possibilita refletir o quanto é necessária a realização de estudos e debates políticos sobre a importância do SUS para a sociedade, pois essas iniciativas esclarecem muitos aspectos desconhecidos e importantes para o aprimoramento da prática cidadã, além dessa falta de conhecimento refletir no desengajamento e despolitização dos movimentos de defesa contra o desmonte do SUS.

Segundo Menicucci ${ }^{30}$, o papel dos movimentos sociais e dos trabalhadores organizados, em particular, na reforma sanitária tem sido tema pouco explorado na saúde coletiva e na historiografia do SUS. Há quem chame a atenção, contudo, para a frágil base de sustentação do SUS entre os sindicatos de trabalhadores. Diferentemente do que ocorreu nos 
processos de implantação de outros sistemas de saúde públicos e universais, o CAWAH acredita que com força e luta o SUS se faz e se sustenta, por essa razão permanece avante na militância.

\section{Considerações finais}

Diante dos embates apresentados, pode-se compreender que os desafios para sustentabilidade do SUS vão desde a formação em saúde, diante do capitalismo acadêmico das instituições privadas e da precarização do ensino público, até os ataques às políticas públicas de saúde que comprometem o direito à saúde da população.

Dessa forma, as experiências aqui apresentadas refletem o comprometimento de estudantes de enfermagem que acreditam no SUS e no potencial de transformação do movimento estudantil.

Ressaltamos a importância do Centro Acadêmico na formação política dos estudantes, mas principalmente a união deste com o conselho de classe, com os Programas de Pós-Graduação em Saúde, com o Conselho
Municipal em Saúde e com todas as pessoas e entidades envolvidas na luta em defesa do SUS.

Parafraseando trecho de canção inédito de Ray Lima e Johnson Soares, acreditamos que 'De sonhação o SUS é feito. Com crença e luta o SUS se faz'. Assim, é preciso fazer da universidade um espaço de construção política para afetar os estudantes para a resistência e formar profissionais comprometidos ético e politicamente com a saúde.

\section{Colaboradores}

Sousa JA (0000-0001-6187-1254)* contribuiu substancialmente para a concepção e planejamento, assim como para a elaboração do rascunho e revisão crítica do conteúdo e participação da versão final do manuscrito. Farias QLT (0000-0003-3877-7598)* e Costa MM (0000-0003-2514-9736)* contribuíram significativamente para a elaboração do rascunho, revisão crítica e aprovação da versão final do manuscrito. Fontenele Júnior AAM (0000-0003-2925-6475)* contribuiu significativamente para a elaboração do rascunho e aprovação da versão final do manuscrito.

\section{Referências}

1. BraghinI KZ, Cameski AS. "Estudantes democráticos": a atuação do movimento estudantil de "direita" nos anos 1960. Educ Soc [internet]. Campinas. 2015 [acesso em 2019 abr 21]; 36(133):945-962. Disponível em: http://www.scielo.br/scielo.php?script=sci_ arttext\&pid=S0101-73302015000400945\&lng=en\&n $\mathrm{rm}=$ iso.
2. Huerta JLH. Representações dos movimentos estudantis brasileiros na imprensa diária durante o ano de 1968. De calabouço à missa do sétimo dia. Hist Educ [internet]. 2018 [acesso em 2019 out 12]; 22(54):4770. Disponível em: 34592018000100047\&lng=en\&n $\mathrm{rm}=$ iso.
*Orcid (Open Researcher and Contributor ID). 
3. Klafke TE, Araújo BR, Cardoso CG. Formação em saúde e protagonismo estudantil: grupo de estudos e trabalhos em saúde coletiva. Psicol. Ensino \& Form [internet]. 2013 [acesso em 2019 out 29]; 4(1):03-19. Disponível em: http://pepsic.bvsalud.org/scielo.php?script=sci_arttext\&pid=S2177$-20612013000100002 \& \operatorname{lng}=p t \& \operatorname{lng}=p t$.

4. Cruz PJSC. Extensão popular: a pedagogia da participação estudantil em seu movimento nacional. Interface (Botucatu) [internet]. 2014 [acesso em 2019 abr 22]; 18(supl2):1591-1592. Disponível em: http:// www.scielo.br/pdf/icse/v18s2/1807-5762-icse-18-s2-1591.pdf.

5. Jornal da USP. Enfermagem é espinha dorsal do sistema de saúde [internet]. 2019. [acesso em 2019 abr 29]. Disponível em: https://jornal.usp.br/atualidades/enfermagem-e-espinha-dorsal-do-sistema-de-saude/.

6. Maranhão T, Matos IB. Vivências no Sistema Único de Saúde (SUS) como marcadoras de acontecimento no campo da Saúde Coletiva. Interface (Botucatu) [internet]. 2018 [acesso em 2019 abr 22]; 22(64):55-66. Disponível em: http://www.scielo.br/scielo.php?pid=S14 $1432832017005008102 \&$ script=sci_abstract\&tlng=pt.

7. Costa FOC, Silveira TCF, Souza IL, et al. O Papel do centro acadêmico na formação cidadão do universitário: Um estudo de caso dos usuários do CABIRG/ UFC. RBCI. 2017; 3(1):05-15.

8. Pires CDO, Melo CMM. Gênese do movimento estudantil na Escola de Enfermagem da Universidade Federal da Bahia (1947-1959). Esc Anna Nery [internet]. 2008 [acesso em 2019 abr 22]; 12(3):437-443. Disponível em: http://www.scielo.br/scielo.php?script=sci arttext\&pid=S141481452008000300007\&lng=pt\&tl ng=pt.

9. Gil AC. Como elaborar projetos de pesquisa. 6. ed. São Paulo: Atlas; 2017.

10. Brasil. Senado Federal. Constituição da República Federativa do Brasil. Brasília, DF; 1988.
11. Silva LSAH. "Nada por nós, sem nós" Lições sobre autonomia e cuidado com pessoas internadas em sofrimento psíquico [dissertação] [internet]. Niterói: Universidade Federal Fluminense; 2017. p. 95. [acesso em 2019 abr 24]. Disponível em: https://app.uff.br/ riuff/bitstream/1/6372/1/Luciana\%20Silverio\%20 Alleluia\%20Higino\%20da\%20Silva.pdf.

12. Conselho Federal de Enfermagem. Justiça garante direito à solicitação de exames por enfermeiros [internet]. Brasília, DF, 2019. [acesso em 2019 abr 20]. Disponível em: http://www.cofen.gov.br/justica-garante-direito-a-solicitacao-de-exames-por-enfermeiros_68886.html.

13. Brasil. Lei $n^{\circ} 7.498$ de 25 de junho de 1986. Dispõe sobre a regulamentação do exercício profissional da enfermagem e dá outras providências [internet]. Diário Oficial [da] República Federativa do Brasil. 25 jun 1986. [acesso em 2019 abr 20]. Disponível em: http:// www.planalto.gov.br/ccivil_03/LEIS/L7498.htm.

14. Conselho Nacional de Enfermagem. Resolução 195/97. Dispõe sobre a solicitação de exames de rotina e complementares por enfermeiros [internet]. Rio de Janeiro, 1997. [acesso em 2019 abr 20]. Disponível: http:// www.coren-ro.org.br/resolucao-cofen-19597-dispoe-sobre-a-solicitacao-de-exames-de-rotina-e-complementares-por-enfermei_777.html.

15. Backes DS, Backes MS, Lorenzini EA, et al. O papel profissional do enfermeiro no Sistema Único de Saúde: da saúde comunitária à estratégia de saúde da família. Ciênc. Saúde Colet. [internet]. 2012 [acesso em 2019 out 13]; 17(1):223-230. Disponível em: http://www. scielo.br/scielo.php?script=sci_arttext\&pid=S1413$-81232012000100024 \& \operatorname{lng}=$ en\&nrm=iso.

16. Araújo JL, Freitas RJM, Guedes MVC, et al. Sistema Único de Saúde e democracia: a enfermagem no contexto de crise. Rev Bras Enferm. 2018;71(4):2066-71.

17. Leonello VM, Oliveira MAC. Educação superior em Enfermagem: o processo de trabalho docente em diferentes contextos institucionais. Rev Esc Enferm USP 2014; 48(6):1093-102. 
18. Slaughter S, Leslie L. Expanding and elaborating the concept of academic capitalism. Organization. 2001; 8:2;154-161.

19. Costa CF, Goulart S. Capitalismo acadêmico e reformas neoliberais no ensino superior brasileiro. Cad EBAPE.BR [internet]. 2018 [acesso em 2019 out. 12]; 16:3. Disponível em: http://www.scielo.br/pdf/cebape/v16n3/1679-3951-cebape-16-03-396.pdf.

20. Pires DEP, Amadigi FR, Albuquerque GL, et al. Enfermagem: Desafios em um contexto complexo [internet]. Coren (SC). $1^{\text {a }}$ Conferência de enfermagem no estado de Santa Catarina. Florianópolis, 2016. [acesso em 2019 abr 23]. Disponível em: http://www.corensc.gov.br/wp-content/uploads/2016/08/TEXTO-NORTEADOR.pdf.

21. Conselho Nacional de Enfermagem. Assembleia legislativa de Minas Gerais. Enfermeiros são contra cursos a distância de enfermagem [internet]. 2018. [acesso em 2019 abr 23]. Disponível em: http://www.cofen. gov.br/enfermeiros-sao-contra-cursos-a-distancia-de-enfermagem_62939.html.

22. Mota DB, Gomes AMT, Silva ACSS, et al. Representações sociais da autonomia do enfermeiro para acadêmicos de enfermagem. Rev Cuid [internet]. 2018 [acesso em 25 abr 2019]; 9(2):2215-2232. Disponível em: http://www.scielo.org.co/scielo.php?script=sci_ar ttext\&pid=S221609732018000202215\&lng=en. http:// dx.doi.org/10.15649/cuidarte.v9i2.528.

23. Neiva MJLMN, Nunes BMVT, Gonçalves LC. Reflexões sobre a trajetória do Conselho Regional de Enfermagem do Piauí. Enferm Foco. 2013; 4(3-4):184186.

24. Zuardi AWA. A Faculdade de Medicina de Medicina de Ribeirão Preto e a Reforma Universitária: O sonho de 1968. Medicina (Ribeirão Preto). 2009; 42(2):16771.
25. Silva MC. A participação da comunidade escolar na gestão democrática: Os mecanismos de participação [TCC] [internet]. Brasília, DF: Universidade de Brasília; 2014 [acesso em 29 abr. 2019]. Disponível em: http://bdm.unb.br/bitstream/10483/9141/1/2014_ MichelePereiraSilva.pdf.

26. Rodrigues PHA. Desafios políticos para a consolidação do Sistema Único de Saúde: uma abordagem histórica. Hist cienc saude-Manguinhos [internet]. 2014 [acesso em 2019 abr. 25]; 21(1):37-60. Disponível em: http://www.scielo.br/scielo.php?script=sci_arttext\& pid=S010459702014000100037\&lng=en.\%20http:// dx.doi.org/10.1590/S0104-59702014000100003.

27. Morosini MVGC, Fonseca AF, Lima LD. Política Nacional de Atenção Básica 2017: retrocessos e riscos para o Sistema Único de Saúde. Saúde debate [internet]. 2018 [acesso em 2019 abr 2019 25]; 42(116):11-24. Disponível em: http://www.scielo.br/scielo.php?pid=SO $10311042018000100011 \&$ script=sci_abstract $\&$ tlng=pt

28. Sobral. Prefeitura Municipal. Secretaria da Saúde e Ação Social. Relatório Coordenação da Atenção Primária à Saúde. Sobral; 2018.

29. Serra Junior GC, Rocha LMLN. A Internet e os novos processos de articulação dos movimentos sociais [internet]. 2013 [acesso em 2019 out 13]; 16(2):205213. Disponível em: http://www.scielo.br/pdf/rk/ v16n2/06.pdf.

30. Menicucci TMG. Público e privado na política de assistência à saúde no Brasil: atores, processos e trajetória [tese]. Belo Horizonte: Universidade Federal de Minas Gerais; 2003.

Recebido em 23/05/2019

Aprovado em 16/10/2019

Conflito de interesses: inexistente

Suporte financeiro: não houve 